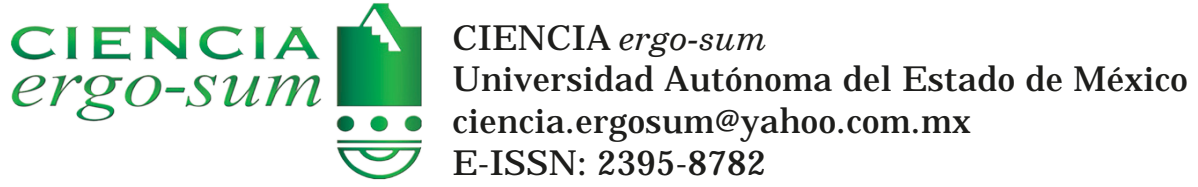

\title{
Significaciones de poder y género en la vestimenta tojolabal del ejido Veracruz, municipio Las Margaritas, Chiapas
}

Pinto Ballinas, Alejandra y Cruz Salazar, Tania

Significaciones de poder y género en la vestimenta tojolabal del ejido Veracruz, municipio Las Margaritas, Chiapas CIE NCIA ergo-sum, vol. 26, núm. 1, marzo-junio 2019|e39

Universidad Autónoma del Estado de México, México

Esta obra está bajo una Licencia Creative Commons Atribución-NoComercial-SinDerivar 4.0 Internacional .

Pinto Ballinas, A. y Cruz Salazar, T. (2018). Significaciones de poder y género en la vestimenta tojolabal del ejido Veracruz, municipio Las Margaritas, Chiapas. CIENCIA ergo-sum, 26(1). https://doi.org/ 10.30878/ces. v26n1a4 


\title{
Significaciones de poder y género en la vestimenta tojolabal del ejido Veracruz, municipio Las Margaritas, Chiapas
}

The tojolabal attire, an analysis about control and subordination

Alejandra Pinto Ballinas

El Colegio de la Frontera Sur, México

Recepción: 26 de abril de 2017

alpinto@ecosur.edu.mx

Aprobación: 04 de octubre de 2017

Tania Cruz Salazar

El Colegio de la Frontera Sur, México

tcruzs@ecosur.mx

\section{RESUMEN}

Se analiza la vestimenta tojolabal femenina del ejido Veracruz, municipio Las Margaritas, Chiapas, como una práctica sociocultural que devela relaciones de poder entre las personas. Los resultados muestran que las significaciones de dicha vestimenta contienen situaciones de dominación masculina y sujeción femenina, relación que se ha construido desde la época baldeana (1900-1942). Se recopilaron datos bibliográficos, etnográficos y se realizaron entrevistas a profundidad. Los testimonios se presentan mediante pseudónimos.

Palabras Clave: vestimenta artesanal, vestir cotidiano, adscripción étnica, dominación, sujeción.

\begin{abstract}
This paper analyzes a traditional clothing called tojolabal in an indigenous community in Las Margaritas, Chiapas as a sociocultural practice that reveals aspects of domination and subjection. The results display that the relationships inside the community are in terms of male domination and female subjection. The relationship, rooted since the early 1900s, the tojolabal people have given cultural significance to wear their traditional clothing. This investigation required historical data, ethnographic register, and depth interviews. We use pseudonyms for collaborators.
\end{abstract}

KEYWORDS: artisanal dress, daily dress, ethnic ascription, domination, subjection.

\section{INTRODUCCIÓN}

La vestimenta artesanal es un objeto artístico, un elemento de adscripción étnica y una práctica sociocultural. Esto refiere a que cada grupo cultural tiene normas que guían el uso de su vestimenta artesanal con el fin de distinguir y ordenar a sus miembros por género, estado civil, edad, generación, entre otras condiciones sociales, asimismo con el fin de comunicar respeto, decencia, sensualidad, opulencia, pobreza, pudor, entre otras connotaciones. De este modo, las modificaciones en los diseños de la vestimenta artesanal, así como el uso o desuso, no son acciones en vano, sino que tienen la intención de corresponder y comunicar determinados ideales.

La modificación o el desuso de una vestimenta artesanal se debe a que la transmisión de esta práctica entre las generaciones de un grupo cultural es discontinua, ya que los acontecimientos de índole social, política, tecnológica, educativa o económica rompen con la continuidad histórica configurando el modo de vida y de pensar de las personas (Mannheim, 1993; Hareven y De Gruyere, 1999), y por lo tanto también modifican los diseños, las denotaciones y connotaciones de su vestimenta artesanal.

En Chiapas, acontecimientos como la creación de los ejidos, la baja del precio del maíz de 1970 y el proceso de urbanización que han tenido las comunidades indígenas desde entonces han influido en las modificaciones 
de la vestimenta artesanal tanto en los diseños como en la importancia de uso (Rus, 2012). La creación de los ejidos liberó a la población indígena del yugo patronal, la cual dejó de sentirse sometida y pudo percibir su vestimenta artesanal como un aspecto étnico de orgullo y no como una marca de acasillamiento. Ante la baja del precio del maíz, las comunidades indígenas hallaron que la comercialización de la artesanía textil era otra fuente de ingresos. Así, la vestimenta artesanal adoptó un valor lucrativo y una consecuente modificación de su diseño original, pues, para atraer más compradores, los artesanos y las artesanas comenzaron a confeccionar una variedad de modelos, y para reducir costos en la elaboración emplearon materiales industrializados y modernos medios de producción (Greenfield, 2004).

Las disposiciones como la educación formal, el ciberespacio, los servicios básicos, los alimentos industrializados y las actividades económicas distintas a la agricultura corresponden al proceso de urbanización que van modificando los contextos indígenas y al mismo tiempo van cambiando la manera de pensar de las generaciones jóvenes sobre sus prácticas culturales. Por este motivo, la preferencia de los jóvenes indígenas hacia la ropa industrializada en lugar de la artesanal es parte de este proceso de urbanización. En cuanto a esto, destaca el hecho de que, mientras los varones han gozado de mayor libertad para elegir su arreglo personal, las mujeres han enfrentado críticas de parte de su comunidad. Para Boyer (2013) este cambio en las jóvenes indígenas se interpreta como una revelación que ellas tienen contra la imagen esperada por su comunidad, y que refiere a vestir ropa artesanal, atender únicamente los quehaceres del hogar y llegar vírgenes al matrimonio.

No obstante, este artículo no aborda el significado que tiene para las jóvenes tojolabales el uso de la ropa industrializada (pantalones de mezclilla, blusas estampadas o con pedrería, chamarras, suéteres, calcetas, etcétera) sino cómo el uso de este tipo de ropa pone de relieve los preceptos construidos por la misma comunidad, los cuales van en función de las relaciones de dominación y sujeción entre hombres y mujeres. Así pues, a la luz de los estudios de género se analiza el caso del ejido Veracruz, un poblado tojolabal que se ubica en el municipio Las Margaritas, Chiapas, donde las jóvenes de esta etnia sólo pueden usar ropa industrializada durante su soltería, ya que al contraer matrimonio están obligadas a vestir el atuendo que se acostumbra en el ejido.

A través de datos etnográficos, bibliográficos y entrevistas a profundidad se documenta que el uso de la vestimenta artesanal de las mujeres tojolabales del ejido Veracruz, denominada como veracruzana, obedece a las relaciones de poder del sistema sexo-género entre los tojolabales, una estructura binaria de hombres y mujeres, con orientación patriarcal y machista, que se ha construido a través de las décadas.

\section{El ejido VeracruZ: un PUeblo tojolabal CON Diferenciales de PODER y GÉNero}

Los ideales de dominación y sujeción que han construido los veracruzanos ${ }^{[1]}$ desde la época baldeana (19001942) ayudan a explicar por qué no aceptan que sus mujeres vistan prendas industrializadas cuando ya están casadas. En la historia de sus habitantes, los hombres han tenido el control en todos los aspectos de la vida, de forma que asumen tener la determinación en el arreglo de sus esposas e hijas.

A saber, los antecesores de los actuales pobladores del ejido Veracruz y que vivieron durante la época baldeana (1900-1942) fueron esclavos en la finca San Mateo y eran llamados baldeanos. ${ }^{[2]}$ Durante esta época el antagonismo entre mestizos e indígenas, y entre hombres y mujeres, estuvo marcado a través de los roles, la lengua, la vestimenta, entre otros aspectos. Los baldeanos usaban prendas impuestas por el dueño de la finca (Gómez-Hernández y Ruz, 1992; Basauri, 1998), que servían para identificar a los tojolabales como la clase trabajadora y se consideraban también como una forma de humillación porque eran hechas a mano con telas baratas, manta o franela; además, siempre estaban sucias y rotas debido a las jornadas de trabajo exhaustivas bajo el sol y a las condiciones antisépticas en las que vivían los tojolabales.

La vestimenta femenina baldeana (figura 1 ) se conformaba por una falda de franela roja o amarilla sin adornos, larga hasta los tobillos y de corte circular, una blusa de manta bordada con bies blanco, mangas cortas y abombadas y un pañuelo blanco. La vestimenta masculina baldeana (figura 2) se conformaba por un sombrero de paja, una camisa de 
manta de cuello redondo, sin botones, mangas largas sin puño y unos pantalones de manta, largos hasta los tobillos de corte recto, los cuales sujetaban con un cinturón de estambre rojo llamado sindor. Por su parte, las familias hacendadas y mestizas vestían ropa confeccionada en máquina de coser, empleaban telas de color, costosas y generalmente decoradas, como popelina, flat, gabardina y seda. Usaban zapatos y cinturones de piel y sombrero tejano.

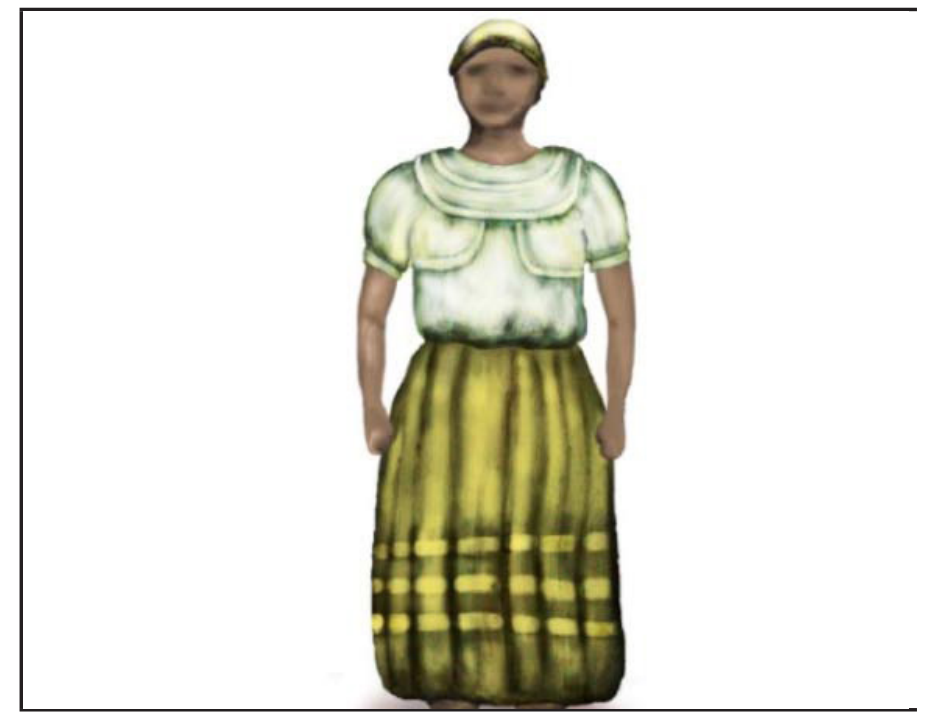

FIGURA 1

Vestimenta baldeana femenina

Fuente: elaboración de Alejandra Pinto Ballinas

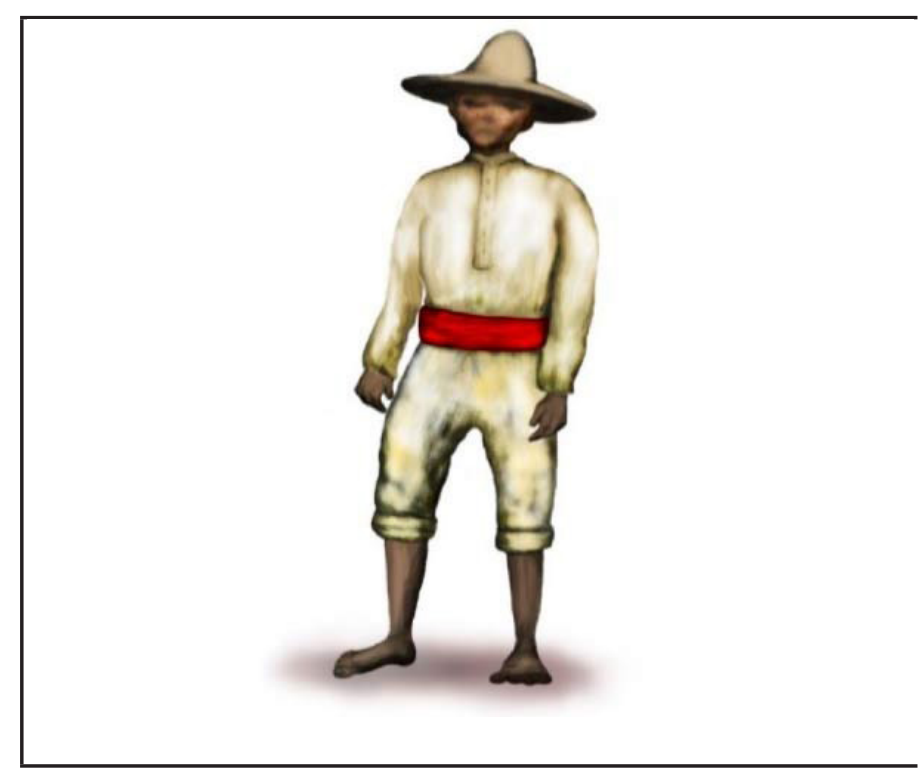

FIGURA 2

Vestimenta baldeana masculina

Fuente: elaboración de Alejandra Pinto Ballinas

Las condiciones de vida de los tojolabales cambiaron durante la época ejidataria (1943-2016), la cual comenzó con la creación del ejido Veracruz en 1943 (Reglamento Interno del Ejido Veracruz, 2015). El paso de la época baldeana a la época ejidataria transformó el modo de vida y de pensar de los tojolabales. Fundamentalmente, los tojolabales configuraron su modo de vida a partir de la intervención de la iglesia católica en 1970, a través de la comunidad de monjas Castalia, ubicada en el municipio de Comitán, Chiapas, y del grupo de maristas "Misión de Guadalupe", ubicado en San Cristóbal de Las Casas, Chiapas. Estos grupos los instruyeron en hábitos de 
higiene, les enseñaron a preparar alimentos como sopa, arroz, calabaza en dulce, y los capacitaron en los oficios de panadería, cocina, carpintería, albañilería, costura, sastrería y tejido. Así, aprendieron a usar la máquina de coser y a confeccionar pantalones, camisas, blusas, faldas plisadas y ropa interior (Testimonios de Teresa Álvarez, José Coello, Francisco Morales, 2016). De igual manera, estos grupos religiosos los ayudaron a despojarse del miedo que tenían hacia el mundo mestizo y los motivaron a revelarse contra el gobierno y a luchar por mejores condiciones de vida (Escalona Victoria, 2004). Sin embargo, este cambio socioeconómico no hizo que las mujeres tojolabales dejaran de estar sometidas a sus esposos. La figura masculina se reafirmó como la ideal para tomar las decisiones, ya que únicamente los varones tojolabales obtuvieron título de propiedad de tierras y la posibilidad de conformar una asamblea ejidal (Gómez-Hernández, 2014).

Además se les formaba para velar por el bienestar de su hogar, lo cual implicaba que viajaran a las ciudades e interactuaran con la población mestiza para obtener servicios de salud, alimentos, vestido o trabajo. De esta manera, les fue necesario aprender a hablar español y sustituir su vestimenta artesanal por un atuendo sastre, similar al que usaban los mestizos en la década de 1970 con el fin de evitar humillaciones y sentirse más seguros al interactuar o hacer negocios con los mestizos, pues la indumentaria constituye un elemento básico de la apariencia física de las personas y ha tenido la función social de identificar a las personas dentro de un grupo u otro (Drucker, 1963)

El atuendo sastre (figura 3) consistía en pantalones de gabardina de corte recto, con bragueta de botones, bolsas en los costados y en la parte trasera, camisas de poliéster corte vaquero con mangas largas, ropa interior, sombrero de palma o tejano y calzado (huaraches, zapatos cerrados o botas de hule).

Por su lado, las mujeres no necesitaron hablar español, pues casi no salían de su comunidad y, si lo hacían, generalmente iban acompañadas de un varón. Respecto a su vestimenta, no la abandonaron, pero sí la hicieron más colorida (figura 4). Las faldas fueron hechas de seda o satén, plisadas y largas hasta las rodillas. Bordaron el pectoral, la golilla y las mangas de sus blusas con hilaza o estambre. Usaron un pañuelo estampado o de un único color. Comenzaron a usar ropa interior y huaraches o zapatos de plástico sin tacón.

Actualmente el ejido Veracruz mantiene una organización patriarcal. Los hombres todavía son quienes tienen la última palabra en la toma de decisiones, heredan título de propiedad de tierras, dictan las leyes, deciden la religión y el partido político de adscripción de su familia y llevan el control de los recursos financieros. Se les considera el sostén del hogar, aunque sus esposas colaboren con el trabajo de la milpa y la venta de sus cosechas; además, pueden regañarlas o incluso golpearlas si consideran que es necesario para corregir su comportamiento (López, 2010).

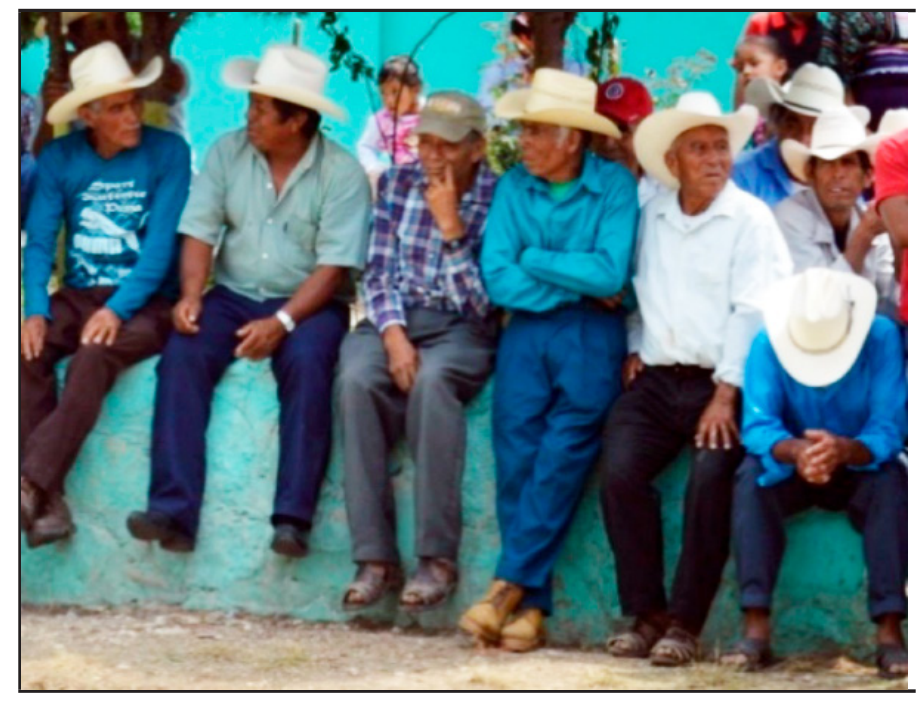

FIGURA 3

Vestimenta sastre (época ejidataria)

Fuente: foto de Alejandra Pinto Ballinas 


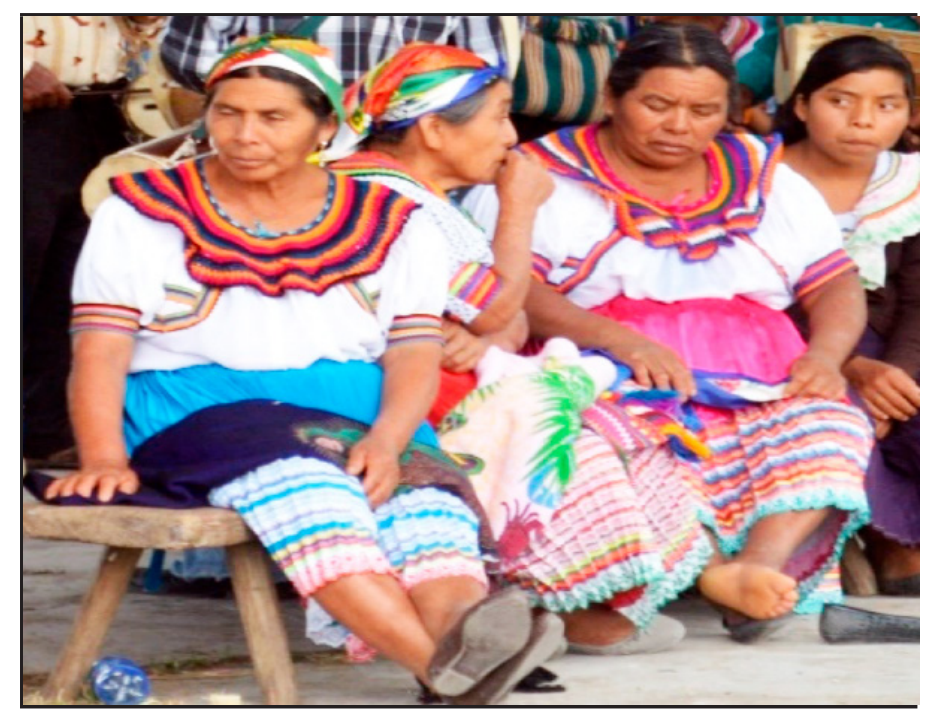

FIGURA 4

Vestimenta femenina (época ejidataria)

Fuente: foto de Alejandra Pinto Ballinas

\section{LA VESTIMENTA VERACRUZANA: REFLEXIONES EN TORNO AL CONTROL DE GÉNERO}

En el ejido Veracruz las mujeres acostumbran usar un vestido de satén o seda floreada, largo hasta la rodilla o a media pantorrilla, con redondel plisado, mangas abombadas y plisadas. Lleva dos cordones anchos y bordados, uno en cada lateral del vestido, los cuales cuelgan de la cadera hasta cruzarse debajo de la espalda. Lleva también una golilla de satén blanco adornada con listones, encajes o espiguillas. Si están dando de mamar, su vestido puede presentar una abertura a la altura del entrepecho, con o sin cierre, para que les facilite la lactancia. Por ser de uso y elaboración exclusiva de las mujeres del ejido Veracruz lo hemos nombrado vestido veracruzano (figura 5).

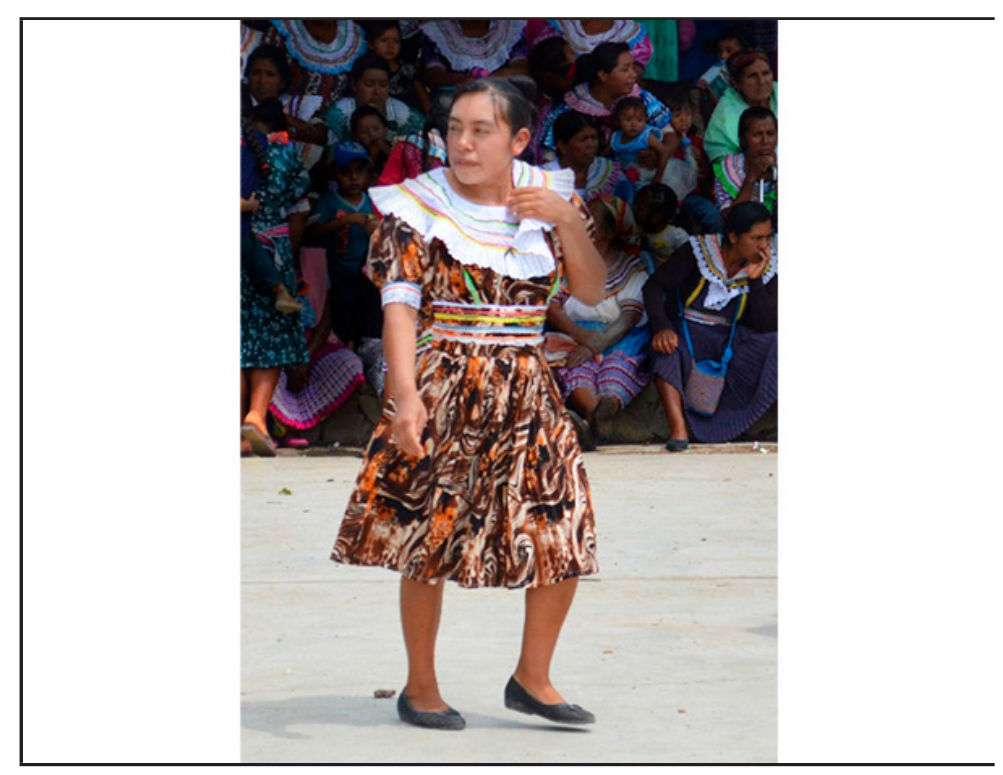

FIGURA 5

Vestido veracruzano

Fuente: foto de Alejandra Pinto Ballinas 
El vestido veracruzano[3] fue desde 1980 hasta principios de 1990 un atuendo de moda para las jóvenes tojolabales, pero cuando comenzaron a vestir ropa industrializada pasó a ser un medio de control moral, es decir, sirvió para mantener la imagen decorosa de la mujer tojolabal. Para los veracruzanos, las mujeres casadas no deben usar ropa entallada como pantalones de mezclilla, ya que las hace ver coquetas y provocativas ante los hombres, lo cual insinúa una posible infidelidad.

Mi novia usa pantalones, pero cuando nos casemos no me va a gustar que ande así. No está bien. No voy a querer que los hombres le estén viendo las nalgas a mi mujer. Con pantalón todo se les ve. Las nalgas bien se ven (Miguel, tojolabal, 20 años de edad, 2016).

El hecho que los veracruzanos vigilen y controlen el arreglo de sus mujeres, y ellas los obedezcan, tiene que ver con los ideales de género con los que fueron formados dentro de su cultura, pues, como es sabido, cada cultura forma a sus hombres y mujeres mediante la asignación de roles, normas y valores con los cuales permiten o restringen a sus miembros de privilegios u oportunidades (Rubín, 1996; Lamas, 2000). En este caso, los hombres veracruzanos no sólo deben poseer un cuerpo de "hombre", tener hijos, esposa y tierras, además deben tener habilidad, ingenio, creatividad, incluso agresividad para actuar en las diversas situaciones de interacción social, así como la capacidad para supervisar y castigar las actividades diarias y el comportamiento de sus esposas (López, 2010), de modo que la autoridad de parte del esposo para restringirle el uso de los pantalones de mezclilla y la obediencia de parte de la esposa no es precisamente una relación dominación-sujeción del modo impositiva, sino que ambas partes han asumido y legitimado que es la manera correcta de comportarse. El caso siguiente ilustra esta relación.

Cuando fuimos a mi casa, allá en la Libertad [comunidad tojolabal] para pedir perdón le dije a mi esposo que iba a llevar mi ropa [se le llama pedir perdón cuando los novios que han huido como pareja regresan a los pocos días a disculparse con los padres de la novia por no haberse casado formalmente]. "Está bien, pero yo voy a escoger lo que te vas a poner y lo que no te vas a poner". "Bueno", le dije. Cuando regresamos me dijo: "De mi parte no me gusta tu ropa, así que ya no lo vas a poner”. ¿Para qué lo traje?, le respondí. "Te dije desde antes que ya no lo ibas a poner", me dijo. Pasó el tiempo y me fui acostumbrando con esta ropa [el vestido veracruzano]. Antes, cuando yo veía mis cosas, cómo me gustaría poner, pero si no quiere, ni modos, la tengo que guardar. Ahora ya me acostumbré a lo que me compra él, de cómo me voy a vestir a su gusto. Mi marido me dice que es mejor el vestido, la falda no, porque cuando me agacho aparece mi culo [forma despectiva de referirse a la forma de las nalgas y las caderas] (Cristina, tojolabal, 33 años de edad, 2016).

En algunos casos, la idea de quién domina y quién obedece es tan fuerte en la mente de las personas que a veces el dominante puede estar ausente y aun así logra tener obedientes quienes se autovigilan para cuidar de no salirse de las normas de un comportamiento que consideran correcto (Foucault, 1992).

Cuando crecí usé vestido [veracruzano]. Empecé a usar pantalón cuando estaba muchacha [soltera]. Como así usaban las muchachas, le pedí a mi mamá que me comprara pantalón. Y como es bien alcahueta mi mamá, "bueno", dijo, y me compró mis pantalones. Luego que me casé otra vuelta volví a usar vestido. Como no es gusto de mi esposo que yo ponga pantalón, lo dejé de poner, según porque no está bien que ande mostrado las nalgas, que se nota cuando camino. Mi esposo no quiso que siguiera poniendo pantalón. No lo usaba siempre, pero él no quiso. Él me decía: "No te pongas pantalón, te van a faltar al respeto y va a ser tu culpa, tú lo andas provocando, eso me va a enojar mucho, ya te lo estoy anticipando que no me gustan esos tus pantalones. Si me entero que estás provocando a los hombres, tus chicotazos te voy a meter". Dejé de usar pantalón. Ya no he vuelto a poner. Yo creo que ahorita ya lo voy a sentir incómodo, ya no me voy a hallar. Luego no vaya a ser que regrese mi esposo de los Estados Unidos y me encuentre con ropa que no le gusta; se va a enojar. Pero, como le digo, quién sabe si quiere regresar (Francisca, tojolabal, 33 años de edad, 2016).

Partiendo de que género es un conjunto de prácticas, valores, roles que les son asignados a los cuerpos sexuados dentro de un grupo cultural, se puede interpretar que el vestido veracruzano es un medio de control de género no solamente de hombres a mujeres, sino entre mujeres tojolabales, ya que este vestido no lo usan en otras comunidades tojolabales. Ellas mismas afirman: "Es que cada comunidad tiene su costumbre de cómo se va 
a vestir", de modo que este vestido representa a la mujer tojolabal del ejido Veracruz. En este poblado, el celo por cuidar el uso exclusivo del vestido se manifiesta tanto por las críticas como al no compartir los conocimientos para su elaboración con cualquier persona, sólo con aquellas que se consideran parte de la comunidad.

Mi cuñada no quería que usara vestido [veracruzano]. Me decían: "No eres de aquí, usa tu falda [entallada], te ves mejor con tu falda, no te queda el vestido [veracruzano]". "Pero yo quiero poner; es pues la costumbre de aquí. No me siento bien usando falda. Yo quiero usar vestido", le decía. Me voy a hallar [acostumbrar] como las señoras de aquí que ya están halladas”. Yo quise perder mi costumbre. No quería mi cuñada que cambiara. "Es muy bueno cómo estás hallada" me decía (Rosa, tojolabal, 37 años de edad, 2016).

Finalmente, como la vestimenta emite mensajes que guardan una lógica identitaria que incluye y excluye a las personas étnica, genérica y generacionalmente (Entswistle, 2002), la voluntad de cambiar una vestimenta tiene que ver con la intención de ser aceptado o aceptada en la sociedad (Lipovetsky, 1987; Simmel, 2015). Así, las fuereñas que llegan a vivir al ejido Veracruz por haber contraído matrimonio cambian sus costumbres indumentarias con el fin de integrarse en su totalidad al ejido. Y, con más exactitud, para formar parte del estatus sociofamiliar que les corresponde como esposas, nueras y madres, de modo que deciden su manera de vestir a voluntad (agencia) en función de la moral de la comunidad (estructura) (Bourdieu, 1979; Entswistle, 2002).

Vine a Veracruz cuando tenía 18 años, cuando me casé. Mi marido llegaba allá en el ejido la Libertad a trabajar como ayudante de albañil; ahí lo conocí. Me habló y le habló a mi papá. Luego de un año de conocernos me trajo acá [en el ejido Veracruz]. Decidí cambiar mi ropa como a los seis meses que estuve aquí. Ya no quería poner falda. Como aquí no ponen así las señoras tuve vergüenza de poner falda, por eso cambié. Al principio sentí como que no me quiero hallar en mi cuerpo, pero poco a poco me hallé al vestido. Así como allá en La Libertad tienen su costumbre, igual aquí tienen su costumbre. Yo no usaba vestido [vestido veracruzano], pero como me casé aquí ya me hallé a usar vestido. Si me hubiera casado donde usan falda, usaría falda; si donde usan traje regional [traje tojolabal de falda plisada y blusa bordada], sólo traje regional usara (Guadalupe, tojolabal, 37 años de edad, 2016).

\section{Conclusiones}

El estudio sociocultural realizado sobre la vestimenta tojolabal hace evidente que ésta ha sido un medio para controlar, disciplinar y apropiarse del cuerpo. Para los hombres del ejido Veracruz, cuando una mujer de su comunidad muestra las caderas, las nalgas y las piernas por el entallado de los pantalones está siendo muy provocativa y coqueta, como un objeto disponible de ser "adquirido". Por ello, una mujer casada no debe vestirse provocativamente porque ya tiene un esposo, que es como si fuera su "dueño".

Sin embargo, no hay que victimizar a las mujeres, ya que ellas finalmente aceptan que una vez casadas la mejor manera de arreglarse es usando la ropa artesanal de su comunidad. Obedecer a la figura masculina es un comportamiento que ha trascendido a través de las generaciones de mujeres tojolabales. De esta manera, el uso del vestido veracruzano está asociado con valores según su género y según su etnia. Se entiende como una relación dominación-sujeción pero no en calidad de imposición, sino un convencimiento de que así debe ser, así se deben vestir.

Por otra parte, el registro histórico de la vestimenta tojolabal muestra que su diseño tiene continuidades. Los elementos que se repiten entre la vestimenta baldeana, la vestimenta de la época ejidataria y la vestimenta veracruzana como la golilla, el plisado, y las mangas abombadas dan continuidad de adscripción étnica y de género, es decir, las identifica como mujeres tojolabales del ejido Veracruz. Por otro lado, los elementos cambiantes como el proceso y los materiales de elaboración han servido para mantener viva esta tradición indumentaria entre las generaciones jóvenes y al mismo tiempo funcionan como marcadores de diferenciación entre generaciones.

El fenómeno sociocultural aquí presentado sobre el uso de la vestimenta tojolabal y la vestimenta industrializada es complejo, ya que por un lado indica que el pensamiento de las mujeres tojolabales se encuentra en un proceso 
de cambio generacional, pues al usar prendas y calzado industrializado muestran que tienen determinación para decidir su arreglo personal. Pero cuando usan nuevamente el traje artesanal muestran obediencia y acatamiento a las normas del vestir predispuestas de su comunidad. Otra cosa que se interpreta de la preferencia por la vestimenta industrializada es que las jóvenes tienen ideas diferentes respecto a sus madres sobre su conformación como mujeres. Para las jóvenes el uso y la confección de la vestimenta artesanal ya no es parte fundamental de su formación, lo que para sus madres era esencial y enorgullecedor.

\section{Prospectiva}

Los temas de investigación como el aquí expuesto pocas veces permiten intervenir en las problemáticas sociales. En este caso, por ejemplo, es incorrecto intervenir para que las mujeres tengan mayor libertad al decidir su arreglo personal, pues se trata de un fenómeno sociocultural que hombres y mujeres han construido por décadas y están de acuerdo. Lo que nos dejan este tipo de investigaciones es conocer las diferentes maneras en que las personas ejercen poder sobre otras y las diferentes formas en que se representan como hombres y mujeres.

Sin embargo, se puede suponer que aun cuando las normas sobre el vestir coadyuvan a que una comunidad mantenga sus tradiciones, dentro de algunas décadas, el uso de ropa artesanal en el ejido Veracruz quedará en el pasado, puesto que las mujeres poco a poco tienen mayores oportunidades de migrar a las ciudades, ya sea por trabajo, estudio o porque las tiendas de ropa están más a su alcance y no comercializan su vestimenta, lo cual les daría motivos para reproducir los conocimientos de costura y confección de su vestimenta tradicional. Además, de alguna manera los hombres veracruzanos van permitiendo que experimenten otro tipo de vestimenta.

Por último, esta investigación sugiere que, además de lo etnográfico y las entrevistas que se puedan realizar a hombres y a mujeres, para entender las diferentes maneras de dominación y sujeción es de gran utilidad revisar la historia del poblado en cuestión, porque las relaciones de este tipo ciertamente se vienen construyendo a lo largo del tiempo.

\section{Referencias}

Basauri, C. (1998). Tojolabales, tzeltales y mayas. Breves apuntes sobre antropología, etnografía y lingüistica. México: Talleres Gráficos de la Nación.

Bourdieu, P. (1979). La distinción. Criterios y bases sociales del gusto. México: Taurus.

Boyer, N. (2013). Los amores locos de una joven chamula. Simpatías materno-filiales y cambio social. EntreDiversidades, 43-85.

Drucker, S. (1963). Cambio de indumentaria. México: Instituto Nacional Indigenista.

Escalona Victoria, J. L. (2004). Cambio político-religioso en una localidad tojolabal del municipio de Las Margaritas, Chiapas. LiminaR. Estudios Sociales y Humanisticos, 2(2), 61-74.

Entswistle, J. (2002). El cuerpo y la moda. Barcelona: Paidós.

Foucault, M. (1992). Las redes del poder. Editorial Almagesto.

Geertz, C. (1973). La interpretación de las culturas. Descripción densa hacia una teoría interpretativa de la cultura. México.

Greenfield, M. P. (2004). Tejedoras: generaciones reunidas. Evolución de la creatividad entre los mayas de Chiapas. México: Ediciones UC.

Gómez-Hernández, A. (2014). La asamblea ejidal: Arena de poder y negociación. México: UNACH. 
Gómez-Hernández, A. y Ruz, M. H. (1992). Memoria baldia, los tojolabales y las fincas. Testimonios. México: UNAM, UNACH.

Hareven, T. y De Gruyer, A. (1999). La generación de en medio. Comparación de cohortes de ayuda a padres de edad avanzada dentro de una comunidad estadounidense. Desacatos, 2.

Lamas, M. (2000). Diferencias de sexo, género y diferencia sexual. Cuicuilco, 7(18), 1-22.

López, M. (2010). Hacerse hombres cabales, masculinidad entre hombres tojolabales. Colección Selva Negra. UNICACH.

Lipovetsky, G. (1987). El imperio de lo efimero. La moda y su destino en las sociedades modernas. Barcelona: Anagrama.

Mannheim, K. (1993). El problema de las generaciones. Reis. Revista española de investigaciones sociológicas, 62, 193-242.

Rubín, G. (1996). El tráfico de mujeres: notas sobre la economía política del sexo, en M. Lamas (Comp.), El género la construcción cultural de la diferencia sexual (pp. 35-96). México: PUEG-Porrúa.

Rus, J. (2012). El ocaso de las fincas y la transformación de la sociedad indígena de Los Altos de Chiapas. México: UNICAH, CESMECA.

Simmel, G. (2015). Filosofía de la moda (segunda edición). Madrid: Casimiro.

\section{Notas}

[1] Llamo veracruzanos haciendo referencia a la población tojolabal del ejido Veracruz.

[2] Los baldeanos refieren aquellos y aquellas tojolabales que trabajaron como esclavos en la finca San Mateo, ubicada en el municipio de Las Margaritas, Chiapas. Los baldeanos recibían del dueño de la finca una gratificación que era insuficiente para cubrir sus gastos, por lo que inevitablemente pedían préstamos al finquero a través de las tiendas de raya. Se endeudaban tanto que para saldar las deudas debían trabajar sin remuneración, pero nunca lograban liquidarlas; por el contrario, sólo aumentaban y se convertían en acasillados (Gómez-Hernández y Ruz, 1992; Basauri, 1998).

[3] El vestido veracruzano fue inventado a finales de 1970 por las veracruzanas que tomaron cursos de costura y confección impartidos por la comunidad de monjas Castalia.

\section{BY-NC-ND}

